DOI: https://doi.org/10.47405/mjssh.v6i11.1137

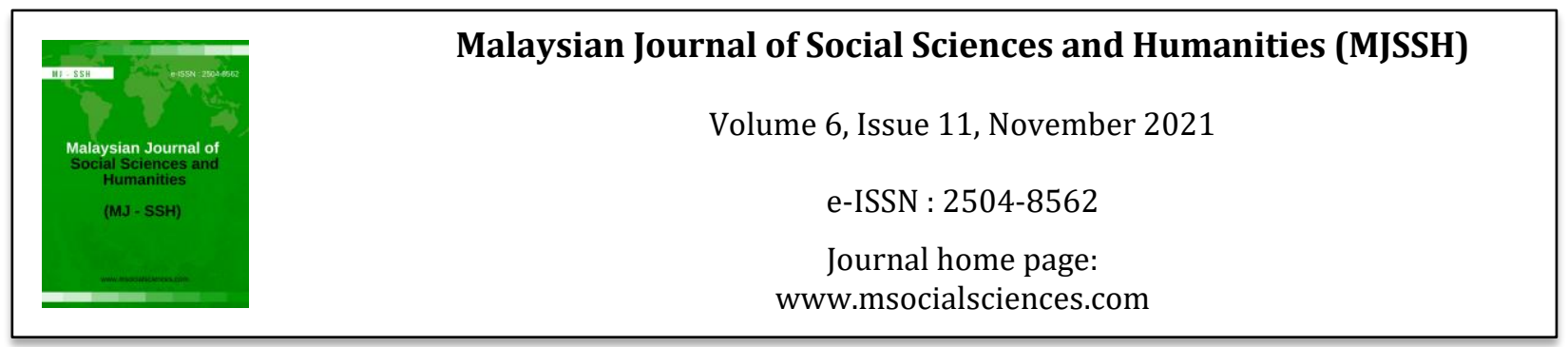

\title{
Aktivisme Sosial dan Pembangunan Modal Insan Menerusi Aktivisme Dakwah, Ilmu Pengetahuan, Kerohanian dan Akhlak
}

\author{
Kartini Kamaruzzaman', Mohd Faridh Hafez Mhd Omar ${ }^{1}$ \\ 1Fakulti Kepimpinan dan Pengurusan, Universiti Sains Islam Malaysia (USIM), Malaysia \\ Correspondence: Kartini Kamaruzzaman (kartinikamaruzzaman@usim.edu.my)
}

\begin{abstract}
Abstrak
Masyarakat mempunyai peranan penting yang berupaya menjadi agen perubahan dalam sesebuah negara. Potensi aktivisme sosial dilihat sebagai aktiviti dan tindakan proaktif masyarakat yang mampu memberi kesan terhadap perubahan sosial, ekonomi, dan politik. Walau bagaimanapun, aktivisme sosial merupakan bidang dominan di barat dan sering dikupas diluar lensa agama. Melalui kaedah sorotan kajian dan konseptual, artikel ini membincangkan penglibatan masyarakat dalam aktivisme sosial menerusi perspektif modal insan. Dapatan dari perbincangan mendapati bahawa kurangnya hubungkait aktivisme sosial dalam aspek modal insan yang berteraskan perspektif Islam. Aktivisme sosial tidak terhasil hanya disebabkan oleh pilihan peribadi masyarakat semata-mata, tetapi perlu diterapkan dengan modal insan yang berteraskan aktivisme dakwah, ilmu pengetahuan, kerohanian dan akhlak.
\end{abstract}

Kata kunci: aktivisme sosial, modal Insan, dakwah, ilmu, kerohanian, akhlak

\section{Social Activism and Human Capital Development Through Da'wah Activism, Knowledge, Spirituality, and Morality}

\begin{abstract}
Society plays an important role to play with a capacity to be the agent of change in a country. The potential of social activism is seen as a proactive activity and action of which society can influence the impact of social, economic, and political aspects. However, social activism is a dominant field in the West in which it is often discussed without considering the role of religion. Through literature review and conceptual methods, this article discusses community involvement in social activism through a human capital perspective. The findings from the discussion found that there is a lack of relevance of social activism in the aspect of human capital based on the Islamic perspective. Social activism does not result only due to the personal choice of society alone but must be applied with human capital based on dakwah activism, knowledge, spirituality, and morality.
\end{abstract}

Keywords: social activism, human capital, dakwah, knowledge, spiritual, morality 


\section{Pengenalan}

Aktivisme sosial merupakan satu kaedah di mana masyarakat yang mempunyai pelbagai latar belakang dapat bersama-sama melibatkan diri untuk melakukan aktiviti dan tindakan demi mencapai sesuatu matlamat. Aktivisme sosial merujuk kepada kepelbagaian aktiviti dan tindakan yang dirancang atau disengajakan di mana fokus aktiviti tersebut adalah untuk mempengaruhi dan memberi kesan kepada perubahan sosio-politik (Brenman \& Sanchez, 2014; Dumitraşcu, 2015; Meikle, 2018). Ia menunjukkan bahawa manusia berupaya menjadi agen perubahan dan tindakan mereka mampu memberi kesan kepada hal ehwal semasa dalam sesebuah masyarakat (Dumitraşcu, 2015; Meikle, 2018).

Melalui aktivisme sosial, manusia dapat mencapai suatu tujuan serta melakukan atau menghalang sebarang perubahan daripada berlaku menerusi pelbagai usaha disamping mempengaruhi individu mahupun kumpulan lain dalam sesebuah masyarakat (Tourine, 1981; Diani, 1992). Ia juga menunjukkan bahawa perkara ini tidak mungkin dapat dicapai oleh individu perseorangan kerana ia memerlukan kerjasama masyarakat secara kolektif. Sebagai contoh, terdapat kajian yang menyatakan aktiviti secara individu berupaya membangkitkan kesedaran, tetapi aktiviti yang dipandu persefahaman kolektif dari banyak gabungan lebih memberi kesan langsung kepada perubahan yang dihasratkan (Healy, Bradley, \& Mukherjee, 2004).

Walau bagaimanapun, aktivisme sosial tanpa berlandaskan Al-Qur'an dan As-Sunnah dan syariat Islam sudah tentunya tidak dapat melahirkan masyarakat rabbani iaitu yang seimbang dalam perihal tadbir urus dunia dan fokus dalam mencapai matlamat akhirat. Aktivisme sosial yang hanya berlandaskan pemikiran akal hanya akan menyebabkan ketidakseimbangan di mana manusia akan bertindak menurut hawa nafsu dan logik akal fikiran. Malah, aktivisme sosial yang keterlaluan dan tidak dikawal boleh menyebabkan perpecahan dalam masyarakat serta memberi kesan yang tidak baik terhadap kelakuan dan akhlak.

Sekaligus, ia menunjukkan pentingnya keperluan modal insan yang dapat memberi panduan kepada manusia agar dapat membimbing setiap tindak-tanduk mereka terutamanya dalam penglibatan aktivisme sosial. Walaupun sorotan kajian berkenaan modal insan ada dibincangkan, ianya lebih tertumpu kepada konteks organisasi dan sumber manusia (Abd. Rahman Ahmad, 2006, Yahaya, 2008; Awang, Basir dan Mohamed, 2019), ekonomi (Mohd Fauzi Hamat, 2012; Mansur, 2013; Mohamed Makhbul \& Abd Latif, 2019) dan pendidikan (Ahmad Badawi, 2007; Mat Lazim, 2012; Zainal Abiddin, 2014; Ma'dan, Ismail \& Daud, 2019).

Sehubungan itu, ia menunjukkan kurangnya perbincangan berkenaan modal insan dalam aspek aktivisme sosial. Justeru, pembangunan aktivisme sosial berpandukan modal insan yang berteraskan syariat Islam amat diperlukan bagi membina sahsiah masyarakat yang berilmu pengetahuan, berkemahiran, beradab dan mempunyai nilai moral yang kukuh. Bahkan kaitan modal insan dan aktivisme sosial merupakan tunjang terpenting yang tidak terpisah di dalam kefahaman Islam dan ia mesti wujud di dalam aktivisme sosial yang dipandu masyarakat Islam (al-Qardhawi, 1992: 12-15).

Perbincangan berkenaan aktivisme sosial perlu dikaitkan dengan modal insan dan peranan individu di dalam masyarakat sebagai khalifah di muka bumi. Agen sosial merupakan makhluk yang diciptakan Allah dan didefinisikan sebagai pemimpin yang tertinggi di muka bumi. Peranan manusia sebagai khalifah juga adalah untuk memastikan peraturan dan hukum yang disyariatkan Allah akan dilaksanakan di muka bumi. Allah berfirman yang bermaksud:

"Sesungguhnya Kami telah menciptakan manusia dalam bentuk sebaik-baiknya." (At-Tin: 4).

Manusia merupakan anggota sosial yang juga merujuk kepada makhluk yang diciptakan Allah dan disempurnakan dengan akal fikiran sebagai sebaik-baik penciptaan (Mat Akhir \& Sabjan, 2014). Kurniaan akal fikiran membolehkan manusia untuk memaknai sesuatu perkara yang berlaku dalam kehidupan seharian mereka meliputi penglibatan dalam aktivisme sosial. Justeru itu, artikel ini 
membincangkan berkenaan aktivisme sosial dan pembangunan modal insan menerusi aktivisme berteraskan dakwah, pendidikan ilmu Islam, kerohanian dan akhlak.

\section{Metod Kajian}

Artikel ini menggunakan metod konseptual model (Jaakkola, 2020) yang bertujuan untuk mengembangkan kerangka dan mengenal pasti hubungan antara konsep. Tujuannya adalah untuk memahami bidang aktivisme sosial serta kaitannya dengan modal insan serta elemen yang terdapat di dalamnya. Oleh itu, ia melibatkan proses pendekatan konsep dan analisa sorotan kajian (Delbridge \& Fiss, 2013; Jaakkola, 2020) untuk membina rasional hubungan antara komponen tersebut. Melalui sintesis sorotan kajian, artikel ini menghuraikan kepentingan memperluaskan kajian berkenaan aktivisme sosial diikuti dengan perbincangan sorotan kajian berkaitan aktivisme sebagai dakwah, kepentingan ilmu pengetahuan, pembangunan kerohanian dan pembentukan akhlak dalam memperkasakan modal insan dan penglibatan masyarakat.

Rajah 1: Pembangunan Konsep Aktivisme Sosial dan Modal Insan Menerusi Dakwah, Ilmu Pengetahuan, Kerohanian dan Akhlak

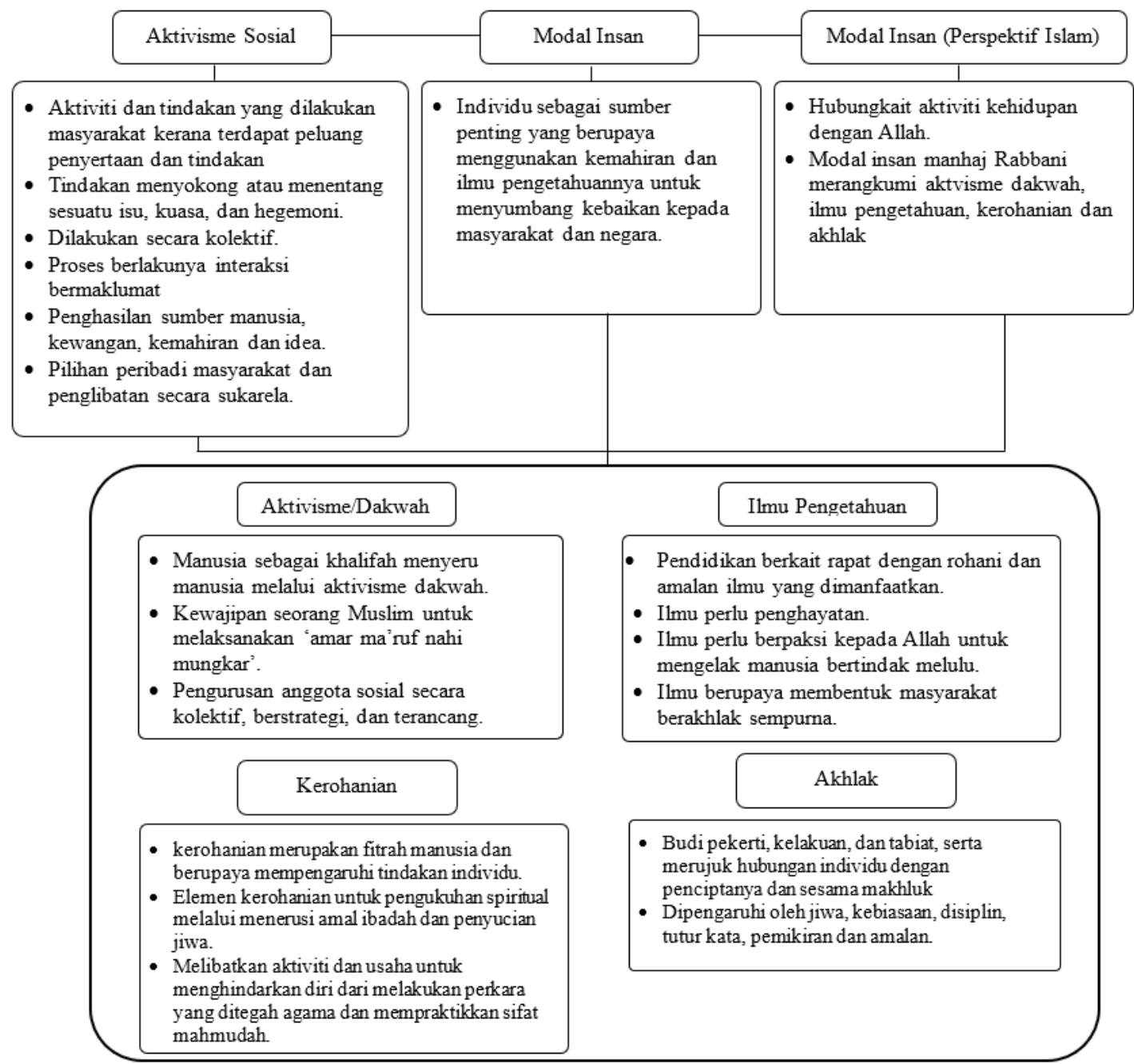

\section{Aktivisme Sosial}

Terdapat pelbagai takrifan aktivisme sosial. Secara amnya, perkataan 'sosial' ditakrifkan sebagai individu atau kumpulan dalam sesebuah masyarakat (Brenman \& Sanchez, 2014; Dumitraşcu, 2015). 
Manakala perkataan 'aktivisme' merujuk kepada aktiviti dan tindakan yang dilakukan kerana terdapat peluang penyertaan dan tindakan (Brenman \& Sanchez, 2014; Dumitraşcu, 2015).

Aktivisme sosial banyak dikaji menerusi bidang sosiologi dan sains sosial. Walau bagaimanapun, takrifan aktivisme hanya tertumpu kepada aspek sosio-politik yang terpisah dari lensa agama. Sebagai contoh, menurut perspektif barat, aktivisme merupakan situasi di mana masyarakat mencapai perubahan sosial secara kolektif (Tilly, 2006) dan berlakunya rangkaian interaksi bermaklumat antara individu atau organisasi yang terlibat dalam konflik politik atau budaya berdasarkan identiti bersama (Diani, 1992).

Aktivisme juga ditakrifkan sebagai proses berlakunya pertukaran maklumat dan interaksi dalam kalangan masyarakat yang mana situasi tersebut berupaya mempengaruhi sistem kepercayaan dan pendapat kepada tindakan yang dilakukan bersama (McCarthy \& Zald, 1977; Tourine, 1981). Terdapat ahli sarjana barat yang mendefinisikan aktivisme sebagai suatu aktiviti rangkaian yang dapat menghasilkan sumber. Sumber tersebut adalah sama ada dalam bentuk sumber manusia, kewangan, kemahiran dan idea yang boleh menggerakkan sesuatu tindakan (della Porta \& Diani, 2006). Aktivisme juga dirujuk sebagai wadah penyertaan bagi aktiviti yang berorientasikan masaalah dan isu sosial. Seterusnya, agensi sosial yang terlibat dalam aktivisme cenderung untuk melakukan tindakan sama ada untuk menyokong atau menentang sesuatu isu, kuasa, dan hegemoni (Melucci, 1996; Brenman \& Sanchez, 2014; Meikle, 2018).

Menurut perspektif konstruktis, aktivisme ditakrifkan sebagai proses pembelajaran yang terhasil dari persekitaran sosial dan melibatkan aktiviti bersama atau secara kolaboratif. Perspektif tersebut menjelaskan bahawa manusia melakukan pelbagai aktiviti bersama seperti melalui komunikasi, interaksi, dan memberikan respons untuk memaknai sesuatu perkara (Dumitraşcu, 2015). Selain itu, istilah aktivisme sosial juga boleh ditakrifkan sebagai aktiviti dan tindakan sama ada yang dirancang atau disengajakan di mana tujuannya adalah untuk memberi kesan kepada perubahan sosial, ekonomi, dan politik (Brenman \& Sanchez, 2014; Dumitraşcu, 2015; Meikle, 2018). Meikle (2018) berpendapat aktivisme merujuk kepada aktiviti yang dilakukan oleh manusia untuk mencapai tujuan, perubahan, dan kesan tertentu menerusi pelbagai usaha untuk mempengaruhi individu mahupun kumpulan dalam sesebuah masyarakat.

Agensi sosial yang terlibat di dalam aktivisme sosial boleh terdiri dari pelbagai lapisan masyarakat dan latar belakang sosial seperti faktor jantina, profesion, dan pendidikan yang berbeza. Aktivisme sosial terhasil disebabkan oleh pilihan peribadi masyarakat dan penglibatan mereka adalah secara sukarela (Brenman \& Sanchez, 2014). Pelbagai aktiviti boleh diklasifikasikan sebagai aktivisme sosial antaranya adalah mengadakan perhimpunan, berkempen, membuat pernyataan terhadap sesuatu isu sosio-politik, mengambil bahagian dalam demonstrasi dan mengekspresikan solidariti. Kesemua aktiviti tersebut menunjukkan bahawa aktivisme saling berkait rapat dengan pengamalan sosial yang membolehkan individu dan kumpulan dalam sesebuah masyarakat untuk memaknai sesuatu perkara (Brenman \& Sanchez, 2014; Dolata, 2017; Earl dan Garret, 2017).

United Nation di dalam laporan yang bertajuk "Social Justice in an Open World The Roles of the United Nations" pada tahun 2006 menyatakan dalam menangani masalah sosial termasuk ekonomi dan krisis politik memerlukan penglibatan langsung daripada pertubuhan aktivisme sosial kerana prinsip gerak kerja yang diperjuangkan adalah berteraskan kepada pembangunan modal insan yang mapan dan keadilan untuk semua. Dan dalam laporan terkini yang dikeluarkan oleh Bennett Institute for Public Policy, Cambridge (2020) turut menyatakan golongan belia merupakan golongan yang terdedah kepada aktivisme sosial, malah turut mengetuai aktivisme sosial pada hari ini dengan objektif membawa perubahan. Namun, Jufitri Joha (2019) mengingatkan adalah penting untuk golongan belia yang terlibat di dalam aktivisme sosial mempunyai panduan objektif dan kefahaman yang jelas bagi mengelakkan tersasar dari aspirasi perubahan yang murni.

Aktivisme sosial bukanlah sesuatu yang hanya melibatkan aktiviti seperti menentang dengan kekerasan atau penglibatan yang mencetuskan konflik. Walau bagaimanapun, aktivisme sosial dapat menghasilkan tindakan dan kesan yang positif kepada masyarakat sekiranya dilaksanakan dengan 
berhemah untuk mencapai tujuan yang tidak bertentangan dengan keselamatan negara dan syariat Islam. Clark (2004) dalam kajiannya menyatakan aktivisme sosial yang berlangsung di Mesir, Jordan dan Yaman dimana objektif aktiviti selari dengan syariat Islam berjaya membawa perubahan khususnya dari aspek sosio-ekonomi dan pendidikan masyarakat. Sehubungan itu, perancangan dan pengisian aktivisme sosial yang baik (dengan fahaman agama yang benar) boleh menyumbang kepada pembangunan modal insan komprehnsif.

\section{Modal Insan}

Modal insan merujuk kepada modal yang bersumberkan manusia atau manfaat yang dapat disumbangkan oleh manusia (Ishak \& Zumrah, 2008; Mat Akhir \& Sabjan, 2014). Modal insan juga ditakrifkan sebagai sumber intelek yang terdapat dalam diri setiap manusia (Dewan Bahasa dan Pustaka, 2007). Ia menunjukkan individu sebagai sumber penting yang berupaya menggunakan kemahiran dan ilmu pengetahuannya untuk menyumbang kebaikan kepada masyarakat dan negara (Abdullah Ahmad Badawi, 2007; Ishak \& Zumrah, 2008).

Modal insan bermaksud keperluan masyarakat untuk "mempunyai jati diri yang kukuh, berketerampilan, berkeperibadian mulia, berpengetahuan dan berkemahiran tinggi" di samping mempunyai keupayaan untuk berfikir secara kritis dan kreatif, menyelesaikan masalah dan berinovasi dalam mencipta peluang baru (Abdullah Ahmad Badawi, 2007:5-6). Ini seiring dengan definisi aktivisme sosial yang menumpukan kepada keperluan penglibatan masyarakat dalam menangani isu sosio-politik (Melucci, 1996; Brenman \& Sanchez, 2014; Dumitraşcu, 2015; Meikle, 2018) atau penglibatan dalam melakukan perubahan sosial kearah yang lebih baik (Diani, 1992; Brenman \& Sanchez, 2014; Dumitraşcu, 2015).

Pembangunan modal insan amat ditekankan di Malaysia kerana ia dapat menyumbang kepada kejayaan negara melalui pembangunan sosio-politik dan kelestarian jati diri masyarakat. Ianya amat penting sehingga disebutkan di dalam Rancangan Malaysia Kedua Belas 2021-2025 (Unit Perancang Ekonomi Jabatan Perdana Menteri, 2020), dengan fokus kepada pembangunan modal insan mahir dan penyertaan masyarakat dalam sektor digital. Penekanan turut diberikan kepada kepentingan pembelajaran dan pendidikan, peningkatan kualiti masyarakat yang berdaya saing, kesepaduan sosial, dan penerapan unsur-unsur ilmu, budaya dan moral.

Meskipun begitu, kerangka modal insan dan aktivisme sosial perlulah berpaksikan kepada Al-Qur'an dan As-Sunnah dan syariat Islam. Sebagai contoh, kerangka modal insan menurut Al-Ghazali adalah melalui pembangunan rohani dan jasmani, hubungan manusia dengan akal, dan hubungan manusia dengan Allah, makhluk dan amalan (Mohd Azaman \& Badaruddin, 2016). Wan Mohd Nor (2019: 229) turut menjelaskan faham kerangka modal insan dari karya Al-Ghazali membolehkan sesorang mempunyai pandangan sarwa (worldview) yang baru terhadap isu-isu semasa dan seterusnya berusaha untuk melakukan perubahan. Manakala modal insan yang diketengahkan oleh Sa'îd Ḥawwā menerusi karya beliau seperti Ihyā' al-Rabbāniyyah atau konsep manhaj rabbani membawa maksud kehidupan yang sentiasa ada hubungkait dengan Allah (Norasid, 2011; Norasid, \& Abdullah, 2019). Pengertian Rabbani tersebut membawa maksud pengabdian diri seseorang insan kepada Tuhannya (Norasid \& Abdullah, 2019).

Justeru itu, kerangka modal insan yang Al-Qur'an dan As-Sunnah mementingkan aktivisme berlandaskan dakwah dan syariat Islam yang disesuaikan dengan tuntutan arus perdana, pembudayaan ilmu Islam, pemantapan kerohanian insaniah, dan pembentukan akhlak Islamiah (Norasid, 2011; Norasid \& Abdullah, 2019).

\section{Aktivisme Sosial dan Dakwah}

Kajian yang dihuraikan oleh pengkaji barat tidak mengangkat agama sebagai sumber utama yang dapat mendorong manusia melakukan aktivisme sosial. Menerusi lensa Islam, pendekatan aktivisme dapat dikaitkan dengan seruan dakwah sebagai aktiviti yang sangat dituntut oleh agama (Norasdi \& 
Abdullah, 2019). Ia mempunyai hubung kait yang jelas dengan peranan manusia sebagai khalifah di muka bumi yang diciptakan Allah (Norasid, 2011; Mat Akhir \& Sabjan, 2014).

Aktivisme menurut sisi pandang Islam turut menyentuh mengenai kewajipan seorang Muslim untuk melaksanakan pendekatan 'amar ma'ruf nahi mungkar' yang mengajak setiap individu untuk mempelawa orang lain berbuat kebaikan dan mencegah segala bentuk kemungkaran (Norasid \& Abdullah, 2019). Masyarakat sebagai agen sosial juga digalakkan memberi nasihat antara satu sama lain untuk memperbaiki kelemahan yang ada serta membina sifat dan karakter insan yang berjaya. Perkara ini disebutkan di dalam Al-Qur'an yang bermaksud:
"Dan hendaklah ada di antara kamu satu puak yang menyeru (berdakwah) kepada kebajikan (mengembangkan Islam), dan menyuruh berbuat segala perkara yang baik, serta melarang daripada segala yang salah (buruk dan keji). Dan mereka yang bersifat demikian ialah orang-orang yang berjaya." (Surah Ali-Imran, Ayat 104).

Ayat tersebut menerangkan tentang seruan untuk bangkit melaksanakan aktivisme dan dakwah untuk menyeru manusia kepada perkara ma'ruf seperti perkara bermanfaat yang bertepatan dengan syariat Islam dan mencegah perkara mungkar seperti kemaksiatan dan perkara-perkara yang bertentangan dengan syariat Islam.

Dalam aktivisme dakwah, perspektif Sa'īd Ḥawwā (disebutkan di dalam Norasid \& Abdullah, 2019) menyatakan usaha mengajak kepada kebaikan dan mencegah kemungkaran adalah wajib bagi setiap individu dan ditakrifkan sebagai fardu ain. Manakala usaha yang sama menerusi penglibatan bersama atau secara kolektif ditakrifkan sebagai fardu kifayah. Hal ini turut memperlihatkan bagaimana Islam memandang aktivisme dakwah sebagai keperluan kepada sistem yang tersusun dan sistematik. Ini juga adalah kerana aktivisme sosial sering dilancarkan menerusi wasilah atau pertalian dengan ahli kumpulan agar sesuatu aktiviti dapat digerakkan bersama komuniti yang lebih besar.

Perkataan ribbiyyūn dan rabbāniyyīn diketengahkan dalam menghurai elemen aktivisme (Norasid \& Abdullah, 2019). Pertama, ribbiyyūn yang dinyatakan di dalam Al-Qur'an menerusi Surah Ali-Imran, ayat 146, bermaksud golongan yang berbuat kebaikan dan amalan yang meningkatkan ketaqwaan sehingga mereka berpegang teguh dengan Allah. Manakala perkataan rabbāniyyīn seperti yang disebutkan dalam firman Allah, Surah Ali-Imran, ayat 79, merujuk kepada para cendekiawan, ulama' dan ilmuan agama Islam. Antara sifat-sifat terpuji golongan rabbāniyyīn yang disebutkan di dalam AlQuran adalah seperti sabar, mempunyai fokus, konsisten, sentiasa bersemangat, dan tidak mudah berputus asa dalam menegakkan syariat Islam.

Oleh yang demikian, kaedah atau uslub aktivisme dakwah perlulah mengikut struktur ilmu pengetahuan dan kerohanian yang jitu. Dalam melakukan aktivisme sosial berteraskan dakwah, etika dan kaedahnya perlulah mengikut panduan yang ditetapkan di dalam Al-Qur'an serta mengikut contoh teladan (uswah) yang ditunjukkan oleh Rasulullah S.A.W dan para sahabat Baginda (Suhid, 2007). Menurut Mustafa Abu Saad (2018) di dalam al-Tarbiyyah min Manzūr wa Manhajiyyah Islāmiyyah turut menjelaskan bahawa peribadi Rasulluah S.A.W adalah contoh terbaik dalam aspek aktivisme sosial yang tidak hanya terhad kepada sahsiah malah melangkaui aspek kepimpinan dan komunikasi. Ia bermaksud, agen sosial juga merupakan pendakwah yang melakukan amalan mulia secara berterusan disamping memimpin orang lain melakukan kebaikan dan menjauhi perkara terlarang dengan kaedah komunikasi yang berkesan.

Selain itu, masyarakat yang terlibat di dalam aktivisme sosial perlulah menjaga adab dan etika. Sebagai contoh, kita perlulah sentiasa menjaga adab terhadap masyarakat Muslim dan bukan Muslim, menjaga hubungan sosial, cara berkomunikasi dan menolak sesuatu pandangan. Ianya adalah kerana setiap aktivisme dan tindakan akan memberi kesan terhadap cerminan diri termasuklah pengetahuan dalam mengendalikan aktivisme, amalan (individu atau organisasi), implementasi perancangan dan pelaksanaan perancangan. Malah, kecanggungan adab dalam beraktivisme sosial turut menjadi punca 
utama kejatuhan komuniti Muslim di mana memberi kesan kepada gerak kerja dan aktiviti yang dirancang dan tidak lagi mendapat penghormatan dari kalangan masyarakat bukan-Muslim (Murad, 1984).

\section{Aktivisme Sosial dan Kepentingan Ilmu Pengetahuan}

Pembangunan modal insan amat menekankan kepentingan masyarakat berpendidikan dan berilmu pengetahuan (Suhid, 2007; Mat Akhir \& Sabjan, 2014). Begitu juga dengan amalan aktivisme sosial yang menganggap ilmu pengetahuan dan kemahiran adalah penting bagi membolehkan sesuatu tindakan, taktik dan strategi dapat dilaksanakan (della Porta \& Diani, 2006).

Dari perspektif Islam, pendidikan turut berkait rapat dengan aspek rohani seseorang yang perlu diisi dengan ilmu pengetahuan serta kemahiran yang dapat dimanfaatkan. Justeru itu, ilmu mempunyai hubungan yang rapat dengan amalan (Sa`ari \& Syed Omar, 2014).

Menurut Al-Ghazali, akal fikiran mempunyai hubungan yang rapat dengan ilmu pengetahuan dan kerohanian (Mohd Azaman \& Badaruddin, 2015) serta amal (Sa`ari \& Syed Omar, 2014). Akal fikiran boleh menjadi sumber kepada ilmu serta bahagian di mana seseorang menilai sesuatu yang baik dan buruk. Al-Ghazali juga menekankan aspek kebijaksanaan (al-hikmah), keadilan (al-adl), keberanian (al-syaja'ah), dan pencegahan diri dari perbuatan mungkar (iffah). Pertama, kebijaksanaan mempunyai kaitan antara ilmu dan amal di mana ia menjadi asas kepada panduan bagaimana seseorang dapat menilai sesuatu yang baik atau tidak. Kedua, keadilan merujuk kepada keupayaan akal fikiran untuk mengawal hawa nafsu secara hikmah. Ketiga, keberanian yang mencerminkan akal fikiran yang berupaya mempertahankan perkara yang haq dan keteguhan jiwa. Keempat, keupayaan akal fikiran untuk berbuat kebaikan dan mencegah diri dari perbuatan tercela (Mohd Azaman \& Badaruddin, 2015).

Pendidikan juga bermaksud ilmu pengetahuan perlu dihayati daripada sekadar menerima. Penghayatan juga bermaksud mendalami ilmu pengetahuan dengan mengaitkan hubungan manusia dengan Allah serta makhluk yang diciptakan-Nya. Dari sudut hubungan dengan Allah, penerimaan dan penghayatan rukun iman dalam aspek ilmu pengetahuan dan pembangunan rohani menjadi tonggak modal insan (Mat Akhir \& Sabjan, 2014). Ilmu pengetahuan tidak memadai sekiranya manusia tidak berpaksikan kepada hubungan dengan Allah kerana ketiadaan asbab tersebut hanya akan membuatkan manusia bertindak mengikut logik akal fikiran dan bertindak secara melulu. Ia berbeza dengan sorotan kajian aktivisme sosial yang sering dibincangkan menurut perspektif barat di mana manusia hanya bertindak mengikut akal, pengetahuan dan kemahiran mereka. Contohnya, sumber utama untuk menggerakkan aktivisme sosial adalah seperti manusia, sumber kewangan, solidariti dan individu yang berpengaruh (McCarthy \& Zald, 1977).

Dalam aspek hubungan dengan makhluk, Al-Ghazali menyarankan setiap manusia untuk mengenali diri sendiri (Mohd Azaman \& Badaruddin, 2016). Seperti yang dihujahkan oleh Al-Ghazali berdasarkan firman Allah yang bermaksud:

"Kami akan perlihatkan kepada mereka tanda-tanda kekuasaan Kami di merata-rata tempat (dalam alam yang terbentang luas ini) dan pada diri mereka sendiri, sehingga ternyata jelas kepada mereka bahawa Al-Quran adalah benar. Belumkah ternyata kepada mereka kebenaran itu dan belumkah cukup (bagi mereka) bahawa Tuhanmu mengetahui dan menyaksikan tiap-tiap sesuatu?" (Surah Al-Fussilat: 53).

Ayat berkenaan menerangkan mengenai kepentingan insan untuk mengenali diri sendiri kerana ia menjadi jambatan kepada pengetahuan hubungan dengan Tuhannya dan seterusnya dengan makhlukmakhluk yang lain. Proses mengenali diri sangat dituntut dalam Islam kerana seseorang tu dapat merungkai siapa yang menciptakannya dan apakah tujuan dia diciptakan di muka bumi. Melalui cara ini, manusia dapat memahami dan memaknai fungsi diri, jiwa dan tindakan yang yang dilakukan.

Perspektif Sa'īd Hawwā (disebutkan di dalam Norasid \& Abdullah, 2019) menerusi konsep manhaj Rabbani turut menekankan isu kepincangan tarbiah Islamiah yang berlaku pada umat Islam dalam era 
globalisasi. Pendidikan yang berteraskan ilmu Islam yang berlandaskan kepada al-Qur'an dan asSunnah adalah penting bagi membentuk masyarakat berakhlak mulia. Ianya bertepatan dengan firman Allah yang bermaksud:

"Tidaklah patut bagi seseorang manusia yang Allah berikan kepadanya Kitab agama dan hikmat serta pangkat Nabi, kemudian ia tergamak mengatakan kepada orang ramai: "Hendaklah kamu menjadi orang-orang yang menyembahku dengan meninggalkan perbuatan menyembah Allah". Tetapi (sepatutnya ia berkata): "Hendaklah kamu menjadi orang-orang Rabbaniyin (yang hanya menyembah Allah Taala - dengan ilmu dan amal yang sempurna), kerana kamu sentiasa mengajarkan isi Kitab Allah itu, dan kerana kamu selalu mempelajarinya." (Surah Al-Imran: 79).

Di dalam ayat tersebut, Allah menyatakan berkenaan kepentingan membentuk golongan masyarakat rabbani yang mempunyai kriteria ilmu pengetahuan yang tinggi serta sentiasa berusaha untuk mengamalkan ilmu tersebut dan menyampaikan kepada orang lain. Antara kriteria pendidikan yang baik dapat dicerminkan melalui ketaatan seorang hamba kepada Tuhannya disamping dapat dilihat dari sudut kebijaksanaan, ketaqwaan, dan usahanya yang berterusan. Ilmu pengetahuan dan pendidikan tidak hanya bersandarkan kepada pemikiran (aqli), tetapi perlu berteraskan kepada ilmu wahyu (naqli).

\section{Aktivisme Sosial dan Kerohanian}

Meskipun bidang aktivisme sosial dari perspektif barat ada membincangkan berkenaan aspek spiritual namun perbincangan adalah terhad. Sumber agama tidaklah dibincangkan secara terperinci tetapi menyentuh aspek bagaimana ianya boleh menjadi sumber 'spiritual' menerusi budaya, identiti, simbol dan nilai-nilai bersama (Melucci, 1985; Wald, Silverman dan Fridy, 2005; Hutchinson, 2012). Terdapat juga pengkaji barat yang menyatakan bahawa elemen agama dapat membangunkan dimensi spiritual dan emosi yang berupaya menggerakkan manusia untuk melakukan perubahan dan aktivisme sosial (Hutchinson, 2012). Meskipun begitu, agama dilihat dalam skop yang terhad iaitu menerusi sistem kepercayaan sebagai kerangka yang memotivasikan penglibatan individu di dalam aktivisme sosial.

Dari lensa Islam, aspek kerohanian merupakan fitrah seorang manusia dan merupakan akar tunjang yang berupaya mempengaruhi tindakan seseorang (Mat Akhir \& Sabjan, 2014). Manusia diciptakan dengan fitrah kejadian berunsurkan rohani dan jasmani (Mohd Azaman \& Badaruddin, 2015). Oleh yang demikian, aktivisme sosial dan modal insan yang baik merujuk kepada keseimbangan antara kedua unsur tersebut. Ternyata di sini aktivisme sosial dan modal insan perlu melihat kepada pembangunan dan keseimbangan rohani dan jasmani sebagai tuntutan tanggungjawab setiap manusia. Maksud kesimbangan adalah ketika mana aspek rohani diberikan keutamaan, aspek jasmani tidak diabaikan (Mat Akhir \& Sabjan, 2014; Sa`ari \& Syed Omar, 2014).

Olahan berkenaan penciptaan manusia dari sudut jasmani diterangkan di dalam Al-Quran dengan diperincikan kriteria penciptaan fizikal manusia manakala unsur rohani merujuk kepada penciptaan manusia yang disempurnakan dengan tiupan roh dan diperintahkan untuk taat kepada Allah. Seperti yang disebutkan di dalam Al-Quran yang bermaksud:

"Kemudian apabila Aku sempurnakan kejadiannya, serta Aku tiupkan padanya roh daripada (ciptaan-Ku), maka hendaklah kamu sujud kepadanya." (Surah AlHijr:29).

Elemen kerohanian untuk pengukuhan spiritual dibincangkan sebagai elemen penting yang perlu dilaksanakan menurut akidah Islamiah iaitu dengan menerapkan pendidikan roh menerusi amal ibadah dan penyucian jiwa. Norasid (2011) secara terperinci mengupas mekanisme dan pemaksaan kerohanian seperti amalan zikir, wirid, qiamullail, dan pembacaan Al-Qur'an. Mekanisme tersebut didokong firman Allah SWT yang bermaksud: 
"(Iaitu) orang-orang yang beriman dan tenang tenteram hati mereka dengan zikrullah". Ketahuilah dengan "zikrullah" itu, tenang tenteramlah hati manusia." (Surah Ar-Ra'd: 28)

Ayat Al-Qur'an tersebut memperincikan kepentingan pembangunan kerohanian manusia dengan amalan mengingati Tuhan (Allah). Menurut Sa‘īd Hawwā (disebutkan di dalam Norasid, 2011), masyarakat masa kini perlu menerapkan amalan zikir bagi meningkatkan keyakinan dan ketaqwaan kepada Allah disamping menempuh cabaran hidup. Mekanisme dan amalan tersebut berupaya memberi kesedaran kepada jiwa insan untuk terus berada dalam landasan kebenaran. Ianya juga sebagai kaedah supaya jiwa manusia kekal bermuhasabah akan kesilapan dan kecuaian yang dilakukan serta sebagai usaha untuk mendapatkan keredhaan Allah. Ianya bertepatan dengan firman Allah yang bermaksud:

\begin{abstract}
"Demi sesungguhnya, adalah bagi kamu pada diri Rasulullah itu contoh ikutan yang baik, iaitu bagi orang yang sentiasa mengharapkan (keredaan) Allah dan (balasan baik) hari akhirat, serta ia pula menyebut dan mengingati Allah banyakbanyak (dalam masa susah dan senang)." (Surah Al-Ahzab: 21)
\end{abstract}

Ayat berkenaan turut memperlihatkan Nabi Muhammad SAW sebagai model ikutan yang perlu dicontohi oleh setiap Muslim. Amalan seperti berzikir, beristighfar, berselawat, dan tadabbur AlQur'an merupakan amalan penting yang diwariskan oleh para Nabi terdahulu. Justeru itu, aspek kerohanian adalah penting bagi membangunkan karakter dalaman manusia lebih-lebih lagi apabila setiap individu terlibat secara langsung atau tidak langsung dalam aktiviti sosial. Pembangunan kerohanian perlu diaplikasikan untuk membina pendidikan spiritual agar manusia tidak hanya memfokuskan hubungan sesama mereka, tetapi mengangkat kepentingan hubungan dengan Allah. Ini amat berbeza dengan perspektif barat, di mana para sarjana hanya menekankan kepentingan sistem hubungan sosial seperti melalui interaksi, komunikasi, rundingan, dan proses membuat keputusan dalam aktivisme sosial (Melucci, 1985; della Porta \& Diani, 2006; Treré, 2018).

Pengisian rohani bagi pembangunan modal insan yang baik melibatkan proses penyucian jiwa atau dikenali sebagai tazkiyah an-nafs (Norasid, 2011; Mat Akhir dan Sabjan, 2014) yang perlu diterapkan dalam konteks aktivisme sosial. Perkataan tazkiyah dari segi bahasa merujuk kepada proses pembersihan atau penyucian. Manakala perkataan An-nafs dari sudut bahasa bermaksud hakikat kejadian manusia yang meliputi hawa nafsu (Mat Akhir dan Sabjan, 2014; Abdullah \& Mat Sharif, 2019). Secara dasarnya, tazkiyah an-nafs bermaksud proses penyucian atau pembersihan diri serta hawa nafsu tidak baik yang berada dalam diri seseorang manusia untuk diletakkan dalam landasan yang bertepatan dengan kehendak syariat Islam (Mohd Azaman \& Badaruddin, 2015).

Proses tazkiyah an-nafs memfokuskan kepada dua cabang utama iaitu at-Takhalli dan at-Tahalli (Mat Akhir \& Sabian, 2014; Mohd Azaman \& Badaruddin, 2015). At-Takhalli merujuk kepada proses penyucian diri dari sifat tercela. Manakala at-tahalli merujuk kepada proses penyucian diri dengan sifat terpuji. Oleh yang demikian, tazkiyah an-Nafs bermaksud proses yang mengandungi aktiviti di mana manusia berusaha untuk menghindarkan diri dari melakukan perkara yang ditegah agama disamping memperbaiki diri dengan mempraktikkan sifat-sifat mahmudah (Mat Akhir \& Sabian, 2014; Mohd Azaman \& Badaruddin, 2015). Ianya amat penting untuk dijadikan sebagai amalan kerana ia bertindak sebagai kaedah yang dapat memandu tingkah laku dan akhlak seseorang. Proses tazkiyah an-Nafs merupakan suatu proses yang penting di dalam Islam, seperti mana firman Allah SWT:

"Sebagaimana (Kami telah sempurnakan nikmat berkiblatkan Kaabah yang Kami berikan kepada kamu itu), samalah seperti (nikmat) Kami mengutuskan kepada kamu seorang Rasul dari kalangan kamu (iaitu Muhammad), yang membacakan ayat-ayat Kami kepada kamu, dan membersihkan kamu (dari amalan syirik dan maksiat), dan yang mengajarkan kamu kandungan Kitab (Al-Quran) serta Hikmat kebijaksanaan, dan mengajarkan kamu apa yang belum kamu ketahui." (Surah AlBaqarah: 151). 
Ayat berkenaan menunjukkan bahawa Islam amat menitikberatkan proses penyucian diri dan jiwa. Peringkat seterusnya merujuk kepada mujadalah al-nafs iaitu usaha untuk melawan nafsu dan syahwat diri dari kemaksiatan (mujadalah al-akbar) dan usaha menentang syirik dan kekafiran (mujadalah alasghar). Ianya diikuti pula dengan riyadah al-nafs iaitu proses melatih jiwa untuk berbuat kebaikan dan cegahan daripada melakukan perkara kemungkaran (Fariza et al., 2015; Mohd Azaman \& Badaruddin, 2015).

Secara terperinci, terdapat tiga kategori nafs yang disebutkan di dalam Al-Quran (Mat Akhir \& Sabian, 2014). Pertama adalah nafs al-mutmainnah yang merujuk kepada jiwa yang cenderung kepada ketenangan, kebahagiaan, dan ketenteraman untuk mendapatkan rahmat dan keredhaan Allah, yang beriman dengan qada' dan qadar Allah serta yang sentiasa mengingati Allah. Seperti yang disebutkan di dalam Al-Quran yang bermaksud:

"Kembalilah kepada Tuhanmu dengan keadaan engkau redha dan diredhai, masuklah golongan hamba-hambaku (yang Ku Redhai) dan masuklah ke dalam syurgaKu." (Surah Al-Fajr: 28).

Kedua adalah nafs al-lawwamah merujuk kepada jiwa yang sering mengkritik diri sendiri oleh kerana kesedaran berkenaan terdapat kekurangan dalam melakukan hal-hal ketaatan dan kebajikan oleh kerana kesilapan dan keburukan yang dilakukan. Ketiga adalah nafs al-ammarah yang merujuk kepada diri atau jiwa yang sering mendorong atau mengajak orang lain untuk melakukan keburukan demi memenuhi keinginan dan hawa nafsunya di mana kesannya akan membawa kepada kebatilan dan kesesatan.

Hakikatnya, ketiga-tiga nafs yang dibincangkan wujud dalam diri setiap manusia dan setiap nafs bersaing antara satu sama lain (Mat Akhir \& Sabjan, 2014). Islam menyatakan nafs adalah fitrah dalam kehidupan manusia. Walau bagaimanapun, setiap diri manusia perlu mengelola nafs yang dapat memberi kebaikan dan manfaat kepada dirinya dan ummah sejagat. Sehubungan itu, Islam amat menganjurkan umatnya untuk mengawal nafsu supaya tidak dicemari dan sentiasa berada dalam keredhaan Allah.

Sebagai contoh, ketiadaan nafsu untuk melakukan aktiviti yang dapat menyumbang kepada kemajuan negara sudah tentunya akan memberikan kesan yang tidak baik kepada kemajuan sesebuah negara itu sendiri. Begitu juga dengan keperluan manusia untuk menjiwai sesuatu perkara agar mereka dapat memaknai dan melakukan tindakan yang bersesuaian dengan perkara tersebut. Oleh itu, nafs perlu lah dikawal sebaiknya agar nafs al-ammarah tidak menguasai diri dan jiwa seseorang. Ini adalah kerana sekiranya nafs al-ammarah menguasi diri dan jiwa seseorang, kelakuan dan sifat tercela dan keji akan ditunjukkan di dalam aktiviti-aktiviti sosial yang boleh dilihat melalui pemikiran, sikap dan tingkah laku negatif.

\section{Aktivisme Sosial dan Akhlak}

Akhlak merupakan sebuah konsep yang sangat berkait rapat dengan pembangunan modal insan serta pendidikan (Suhid, 2007). Akhlak bukan sahaja merujuk kepada budi pekerti, kelakuan, dan tabiat, bahkan ia merangkumi hubungan individu dengan penciptanya serta sesama makhluk yang lain (Mat Akhir \& Sabjan, 2014). Islam mementingkan pembangunan akhlak dan insan yang beradab. Menurut Suhid (2007:169), kata dasar ' $t a$ 'dib' (pendidikan) iaitu 'addaba' bermaksud mendidik dan mengajar akhlak atau adab. Sekiranya aktivisme sosial membawa erti peranan anggota masyarakat dalam melakukan tindakan untuk mencapai kebaikan bersama, maka ianya perlulah dipandu dengan akhlak dan adab yang baik.

Perspektif Islam amat menekankan pendidikan akhlak dan adab melalui pemantapan agama dan kerohanian. Pembentukan akhlak dipengaruhi oleh situasi nafs seperti yang dinyatakan oleh AlGhazali di mana modal insan turut dibangunkan menerusi pembangunan akhlak (Mohd Azaman \& Badaruddin, 2015). Beliau memberikan fokus kepada aspek tazkiyah an-nafs melalui hujahan 
bagaimana hati boleh mempengaruhi pemikiran dan emosi. Seterusnya bagaimana perkara tersebut boleh memberi implikasi kepada tindakan, tingkah laku, dan hubungan sosial.

Dari sudut pandang yang lain, Ibn Miskawayh (1961:36 disebutkan di dalam Mat Akhir \& Sabjan, 2014) menyatakan bahawa akhlak terbentuk dari jiwa yang dibina oleh adat, kebiasaan dan disiplin. Ia juga dipengaruhi oleh pemikiran dan amalan atau perilaku seharian yang boleh menyentuh aspek jiwa dan rohani seseorang. Secara dasarnya, akhlak yang baik dibentuk oleh jiwa dan rohani yang bercirikan nafs al-lawwamah (jiwa yang sering bermuhasabah) dan al-mutmainnah (jiwa yang tenang dan tenteram). Manakala jiwa al-lawwamah pula merujuk kepada jiwa yang mendorong seseorang kepada keburukan didorong dengan hawa nafsu.

Perbincangan berkenaan akhlak juga perlu melihat dimensi al-khuluq yang bermaksud tingkah laku dan al-khalq yang bermaksud bentuk kejadian seseorang (Mat Akhir \& Sabjan, 2014). Islam amat menekankan kebaikan pada tingkah laku dan penampilan lahiriah individu. Penampilan luaran (jasad) seseorang dapat dicerminkan dengan penampilan dalaman (nafs). Justeru itu, manusia bukan sahaja menunjukkan penampilan lahiriah, bahkan membawa bersama jiwa (nafs) yang mempengaruhi pembawaan diri mereka sama ada dalam bentuk terpuji (mahmudah) atau tercela (mazmumah) (Mat Akhir \& Sabjan, 2014).

Dalam keterlibatan aktivisme sosial, menjadi tanggungjawab setiap individu yang beriman untuk mencontohi akhlak dan sifat-sifat terpuji yang ditunjukkan oleh Nabi Muhammad SAW. Ini termasuklah dalam apa jua aktiviti-aktiviti sosial di mana seseorang Muslim perlu menjaga kelakuan dan akhlak. Ianya penting bagi mengelakkan percakapan yang kasar, amalan menuding jari pada satu pihak dan menunjukkan sikap panas baran. Pembangunan modal insan yang baik merangkumi akhlak dan pembentukan jiwa yang baik melalui proses tazkiyah an-Nafs. Ini bertepatan dengan firman Allah yang bermaksud:
"Demi diri manusia dan Yang menyempurnakan kejadiannya (dengan kelengkapan yang sesuai dengan keadaannya); Serta mengilhamkannya (untuk mengenal) jalan yang membawanya kepada kejahatan, dan yang membawanya kepada bertaqwa; Sesungguhnya berjayalah orang yang mensucikan jiwa itu (dengan iman dan amal kebajikan); Dan sesungguhnya hampalah orang yang menjadikan dirinya terbenam dari kebersihan jiwa (dengan sebab kekotoran maksiat)." (Surah As-Shams: 7-10)

Dalam konteks hidup bermasyarakat, Islam amat menyarankan kehidupan yang dapat dijalani secara bersama dengan mengamalkan akhlak yang baik. Islam juga mementingkan keseimbangan dunia dan akhirat dan menolak gaya hidup yang mengasingkan diri. Oleh yang demikian, meskipun aktivisme sosial melibatkan aktiviti-aktiviti seperti menggalakkan atau menghalang isu berkaitan sosial, politik, dan ekonomi untuk membuat perubahan dalam masyarakat, tingkah laku dan adab perlu dijaga. Seperti yang disebut di dalam Al-Quran yang bermaksud:

"Dan carilah (pahala) negeri akhirat dengan apa yang telah dianugerahkan Allah kepadamu, tetapi janganlah kamu lupakan bagianmu di dunia dan berbuat baiklah (kepada orang lain) sebagaimana Allah telah berbuat baik kepadamu, dan janganlah kamu berbuat kerosakan di bumi. Sesunguhnya Allah tidak menyukai orang yang berbuat kerosakan.” (Surah Al-Qasas: 77).

Akhlak mencerminkan keperibadian yang dipengaruhi oleh nafs yang mencorakkan pemikiran, katakata, dan tindakan seseorang. Nafs yang dikemudi dengan baik akan membawa diri kepada kebaikan manakala nafs yang tidak dikawal berlandaskan syariat Islam akan membawa kepada keburukan dan kerosakan (Norasid \& Abdullah, 2019). 


\section{Kesimpulan}

Masyarakat berupaya menjadi agen perubahan dalam sesebuah negara menerusi aktivisme sosial. Walau bagaimanapun, kesan dan impak aktivisme sosial yang positif bergantung kepada implementasi modal insan yang efektif. Di dalam artikel ini, dibincangkan kelompangan aktivisme sosial menurut perspektif barat yang tidak menjadikan agama sebagai sumber utama yang boleh memperkasakan penglibatan masyarakat secara positif di dalam aktivisme sosial.

Perbincangan di dalam artikel ini turut menunjukkan kepentingan hubungkait aktivisme sosial dan modal insan di mana agama Islam menjadi teras dalam memperkasakan aktivisme dakwah, ilmu pengetahuan, kerohanian, dan akhlak. Setiap satu komponen memainkan peranan penting dalam melahirkan masyarakat berperanan dan seimbang agar tindakan manusia tidak hanya tertumpu kepada akal fikiran dan hawa nafsu.

Al-Qur'an dan As-Sunnah perlu dirujuk dan dijadikan sebagai panduan agar setiap tindakan dan penglibatan masyarakat di dalam aktivisme sosial dapat dilaksanakan dan dikawal sebaiknya. Aktivisme bukan sekadar tindakan sosial yang dilakukan kerana terdapat peluang penyertaan dan sumber manusia, kewangan, dan kemahiran. Walau bagaimanapun agen sosial perlulah menjadikan 'amar ma'ruf nahi mungkar' sebagai seruan mengajak kepada kebaikan dan mencegah kemungkaran.

Penglibatan dan pelaksanaan aktivisme sosial perlulah didokong dengan ilmu pengetahuan agar setiap amalan dan tindakan tidak merosakkan fungsi kerohanian dan akal fikiran. Setiap aktiviti yang dijalankan perlulah berpaksikan kepada hubungan dengan Allah disamping menjaga keharmonian hubungan sesama manusia. Sumber agama juga perlu dilihat melangkaui aspek budaya, simbol, dan identiti. Ianya adalah kerana agama Islam bukan sahaja bertindak sebagai sistem kepercayaan, tetapi melengkapi fitrah nafs manusia yang inginkan kebaikan dalam kehidupan mereka. Meskipun begitu, nafs perlulah dikawal dengan sebaiknya agar dijauhi dari sifat keji dan tercela.

Perbincangan juga menunjukkan bahawa modal insan dan komponen akhlak sebagai tunjang penting dalam aktivisme sosial. Meskipun aktivisme sosial berupaya menggerakkan masyarakat untuk bersama-sama menangani isu dan permasalahan sosial, kepincangan dari akhlak di kalangan agen sosial sudah semestinya mampu melumpuhkan kesejahteraan sesebuah negara. Oleh yang demikian, aktivisme sosial juga perlu berlandaskan modal insan dan pembentukan akhlak yang kukuh agar kestabilan fikiran, emosi, dan tingkah laku dapat dijaga. Kaedah aktivisme sosial dan modal insan melalui elemen dakwah, ilmu pengetahuan, kerohanian, dan akhlah perlu dipraktikkan dan diamalkan oleh masyarakat untuk mengekalkan kesejahteraan bersama dan menjaga ketamadunan manusia yang beradab.

\section{Rujukan}

Abdul Hakim Abdullah, Ab Aziz Sulaiman \& Wan Ismail Wan Abdullah. (2015). Faktor-faktor yang mempengaruhi motivasi terhadap pembelajaran bahasa Arab. Jurnal Islam dan Masyarakat Kontemporari, 10(2), 104-121.

Al-Qur'an

Abdullah, A. and Mohd Sharif, M. F. (2019) The Concept of Islamic Personality and Spiritual Development. International Journal of Academic Research in Business and Social Sciences, 9(9), 936-949.

Abdullah Ahmad Badawi. (2007). Pelan Induk Pembangunan Pendidikan 2006 - 2010 (RMK-9), Putrajaya International Convention Centre (PICC), Putrajaya.

Abd. Rahman Ahmad. (2006). Pembangunan Modal Insan Apa dan Kenapa Perlu Dalam Konteks Organisasi di Malaysia. Alor Setar: Human Resource Academy.

Al-Ghazali, Abu Hamid Muhammad Bin Muhammad. (1994). Revival of Religious Learnings: Imam Ghazzali's Ihya Ulum-Id-Din, Vol. III. Karachi: Pakistan. 
Al-Qardhawi, Yusuf. (1992). The Priorities of The Islamic Movement in the Coming Phase. Cairo: AlDar.

Awang, Sa'adi, Basir Siti Arni, dan Mohamed, Hasan Al-Banna. (2019). Cabaran Dalam Pelaksanaan Program Pembangunan Modal Insan (PMI) di Jabatan Kemajuan Islam Malaysia (JAKIM). Jurnal Hadhari, 11 (1), pp. 87-105.

Brenman, M. and Sanchez, T. W. (2014). Social Activism. In Alex C. Michalos (ed.), Encyclopedia of Quality of Life and Well-Being Research (pp. 6012-6017). London: Springer.

Clark, J. A. (2004). Islam, charity, and activism: Middle-class networks and social welfare in Egypt, Jordan, and Yemen. Bloomington: Indiana University Press

Sa`ari, C. Z. dan Syed Omar, S. F. (2014). Implementasi Tasawuf dalam Penghayatan Rukun Islam dan Pengaruhnya kepada Penyucian Jiwa (Tazkiyah Al-Nafs) Menurut Sa`id Hawwa. MANU, 20, 165-185.

Delbridge, R., and Fiss, P. C. (2013). Editors' comments: Styles of theorizing and the social organization of knowledge. Academy of Management Review, 38(3), 325-331. della Porta, D. and

Diani, M. (2006) Social Movement: An Introduction. Oxford: Blackwell Publishing.

Dewan Bahasa dan Pustaka. (2007) Khidmat Nasihat: Modal Insan https://prpm.dbp.gov.my/Cari1?keyword=modal \&d=175768\&

Diani, M. (1992). The Concept of Social Movements', The Sociological Review 1992, 1-25.

Dolata, U. (2017) 'Social movements and the Internet: The sociotechnical constitution of collective action', Stuttgarter Beiträge zur Organisations- und Innovations forSozialwissenschaften, Universität Stuttgart, Stuttgart

Dumitraşcu, Veronica. 2015. Social Activism: Theories and Methods. Revista Universitară de Sociologie, 84 (2015), 1-11.

Earl, J. and Garret, R. K. (2017). The New Information Frontier: Toward a More Nuanced View of Social Movement Communication. Social Movement Studies, 16(4), 479-493.

Healy, G., Bradley, H., \& Mukherjee, N. (2004). Individualism and collectivism revisited: a study of black and minority ethnic women. Industrial Relations Journal, 35(5), 451-466.

Hutchison, E. D. (2012). Spirituality, Religion, and Progressive Movements: Resources and Motivation for Social Change. Journal of Religion and Spirituality in Social Work: Social Thought, 31, 105-127.

Jaakkola, E. (2020). Designing Conceptual Articles: Four Approaches. AMS Review, (2020) 10, 18-26.

Joha, Jufitri. (2019). Siri\#4 Bicara Cendekiawan Mulia: Aktivisme Mahasiswa \& Belia: Menasihat atau Menggugat?". Layari https://www.youtube.com/watch?v=2mcmh5C60gg Akses pada 8 Oktober 2021.

Ma'dan, Marfunizah., Ismail, Muhammad Takiyuddin., dan Daud, Sity. (2019) Importance of Human Capital Development and Competitiveness in Enhancing Competency Level Among Malaysia University Graduates: Literature Review. Journal of Social Science and Humanities, 16 (8), 1-15.

Mansur, Kasim. (2013) Pembentukan Modal Insan Cemerlang: Pendekatan Ekonomi Islam. Sabah: Penerbit Universiti Malaysia Sabah.

Ishak, M. dan Zumrah, A. R. (2008) Pendidikan Asas Pembangunan Modal Insan. Prosiding PERKEM III, Jilid I (2008), 327-331.

Mat Akhir, N. S. \& Sabjan, M. A. (2014). Pembangunan Modal Insan Dari Perspektif Kerohanian Agama: Islam Sebagai Fokus. Journal of Human Capital Development, 7 (1), 33-47.

McCarthy, J. D. and Zald, M. N. (1977). Resource Mobilization and Social Movements: A Partial Theory. American Journal of Sociology, 82(6), 1212-1241.

Meikle, Graham. (2018). The Routledge Companion to Media and Activism. Abingdon, Oxon: Routledge.

Melucci, A. (1985) The Symbolic Challenge of Contemporary Movements. Social Research, 52(4), Social Movements (WINTER 1985), 789-816.

Melucci, A. (1996) Challenging Codes: Collective Action in the Information Age. Cambridge: Cambridge University Press.

Mohamed Makhbul, Zafir Khan dan Abd Latif, Mohd Nazmy. (2019). Mengurus Modal Insan Dalam Industri 4.0 Ke Arah Kecemerlangan Negara. Journal of Social Sciences and Humanities, 16(6), $1-13$.

Mohd Azaman, F. N. dan Badaruddin, F. (2016) Nilai-nilai Pembangunan Modal Insan Menurut AlGhazali. International Journal of Islamic and Civilizational Studies, 01, 11-27. 
DOI: https://doi.org/10.47405/mjssh.v6i11.1137

Mat Lazim, Norain. (2012). Universiti, Pembangunan Modal Insan dan Penumpuan Ruang Komuniti Pendidikan Tinggi di Malaysia: Satu Ulasan Kritis. Journal of Social Sciences and Humanities, 17(2), 308-327.

Murad, K. (1984). The Islamic movement: dynamics of values, power and change. United Kingdom: The Islamic Foundation.

Mustafa Abu Saad. (2018). al-Tarbiyyah min Manzūr wa Manhajiyyah Islāmiyyah. Kuwait: Alebdaa AlFekry.

Norasid, M. A. (2011). Manhaj Rabbani oleh Sa‘īd Hawwā dalam Pembangunan Modal Insan: Tumpuan kepada Karya al-Asās fī al-Tafsīr. Jurnal Usuluddin 33 (Januari - Jun 2011), 89-112.

Norasid, M. A. dan Abdullah, M. (2019). Gagasan Pembangunan Modal Insan Rabbani oleh Sa'īd Hawwā dalam al-Asās fĩ al-Tafsīr: Ke Arah Pemerkasaan Kader Dakwah. Jurnal Usuluddin, 47 (Khas), 25-48.

Suhid, A. (2007). Pengajaran Adab dan Akhlak Islam Dalam Membangunkan Modal Insan. MALIM: Jurnal Pengajian Umum Asia Tenggara, 8, 167-178.

Tilly, C. (2006) Regimes and Repertoires. London: The University of Chicago Press.

Tourine, A. (1981) The Voice and the Eye: An Analysis of Social Movements. Cambridge: Cambridge University Press.

Unit Perancang Ekonomi Jabatan Perdana Menteri. (2020). Rancangan Malaysia Kedua Belas 20212025 (RMKe-12), Sesi Libat Urusan Dalam Talian: https://www.mohr.gov.my , TownHRMK12DSMN

Wald, K. D., Silverman, A. D. and Fridy, K. S. (2005). Making Sense of Religion in Political Life. Annual Review Political Science, 8, 121-43.

Wan Daud, WMN. (2019). Budaya Ilmu Makna dan Manifestasi dalam Sejarah dan Masa Kini. Kuala Lumpur: CASIS, UTM.

Yahaya Ibrahim dan Abd. Hair Awang. (2008) Pembangunan Modal Insan: Isu dan Cabaran. Bangi: Penerbit UKM.

Zainal Abiddin, Norhasni. (2014) Senario Pembangunan Modal Insan Dalam Pendidikan Tinggi di Malaysia. Jurnal Kajian Pendidikan, 95-104. 